\title{
ANÁLISE DE DIFERENTES TIPOS DE CEVAS NO MONITORAMENTO \\ DE POPULAÇÕES SELVAGENS DE JAVALI (Sus scrofa) E \\ PREJUÍZOS OCASIONADOS EM PLANTAÇÃO DE MILHO NO \\ INTERIOR DO MUNICÍPIO DE CAÇADOR
}

Analysis of Different Types of Baits in Monitoring of Populations of Wild

Boar (sus scrofa) and Damages Arising in Planting Corn on the Inside of

the City Caçador

Anderson Clayton Copini ${ }^{1}$
Rosane Miozzo ${ }^{2}$
Marcos A. Tortatto ${ }^{3}$
Carlos H. Salvador ${ }^{4}$
Recebido em: 20 set. 2012
Aceito em: 14 jun. 2013

\section{RESUMO}

Espécimes de javali (Sus scrofa), originários da Eurásia, foram introduzidos na América Latina como fonte alternativa de proteínas através da comercialização de sua carne. Entretanto, não houve o manejo adequado dessa espécie que se adaptou aos diversos ecossistemas em que foi introduzido, tornando-se exótica de grande importância econômica e ecológica. Verificou-se, nos últimos anos, o aumento populacional

\footnotetext{
${ }^{1}$ Acadêmico do Curso de Ciências Biológicas da Universidade Alto Vale Rio do Peixe UNIARP, Caçador/SC. e-mail: copinicop@gmail.com.

2 Mestre em Ciências da Saúde Humana pela Universidade do Contestado - UnC, Campus de Concórdia. Graduação em Ciências Biológicas pela Universidade Federal de Santa Catarina e mestrado em Ecologia Conservação pela Universidade Federal do Paraná (2009).

3 Graduação em Ciências Biológicas pela Universidade Federal de Santa Catarina e mestrado em Ecologia Conservação pela Universidade Federal do Paraná.

${ }^{4}$ Graduação em Ciências Biológicas pela Universidade Federal de Santa Catarina e mestrado em Ecologia pela Universidade Federal do Rio de Janeiro. Doutorando em Ecologia pela UFRJ.
} 
descontrolado de javali (S. scrofa) no município de Caçador, concomitantemente a outras regiões do estado de Santa Catarina, principalmente em ecossistemas pertencentes à Floresta de Araucária, devido ao fato de alimentar-se do fruto do pinheiro (Araucaria angustifolia) sazonalmente. Com uma população cada vez maior e sem predadores naturais, espécimes de javali vêm ocasionando significativos impactos negativos: desequilibram o ecossistema, sendo competidores diretos por alimento e habitat de espécies endêmicas ou naturais; atacam plantações rurais, principalmente de milho, ocasionando significativas perdas econômicas; podem, ainda, cruzar com porcos (Sus scrofa domesticus) podendo transmitir uma gama de doenças e interferir negativamente no comércio de carne suína catarinense, principalmente o externo. $O$ objetivo deste trabalho foi avaliar diferentes tipos de ceva - sal mineral, milho, natural e combustível diesel - no monitoramento de populações selvagens de javali, realizada em área de mata nativa pertencente à Empresa Agropecuária de Pesquisa e Extensão Rural de Santa Catarina - EPAGRI, Estação Experimental de Caçador, com a finalidade de verificar a efetividade na atração dos espécimes. Para averiguar os impactos econômicos ocasionados por populações de javali, uma plantação de milho com sessenta (60) hectares, pertencente à fazenda Rio dos Patos, localizada na divisa entre os municípios de Caçador e Lebon Régis, foi avaliada quanto à presença de espécimes de javali e ao número de plantas danificadas por eles durante o mês fevereiro do ano de 2012. Registros fotográficos foram feitos bem como a obtenção de depoimentos de agricultores da região para corroborar os fatos relatados. Pode-se concluir dos trabalhos que a isca com maior atividade de ataque do animal foi a de milho, bem como a área em que o animal atacou algumas lavouras na região, depredando quase $70 \%$ da área plantada.

Palavras-chave: Sus scrofa, javali, ceva, wild boar.

\section{ABSTRACT}

Specims of boar (Sus scrofa), originating gives Eurasia, Latin America from aplicating as alternative protein font Through you comercialization of meat. Meanwhile, no more or appropriate species management that adaptou years various am ecossistems introduced them, making-is uma exotic big species economic importance and ecological. Verificou-is, we recent years, or increased pitch population boar (S. scrofa) of Caçador city not concomitantly to otthers rergions of state of Santa Catarina, mainly $e$ belong to ecossistems of Araucaria Forest, this species due feed-be do fruit do pine (Araucaria angustifolia), seasonally. With a population increasingly naturals and no greater predators, causing comes javali especims of 
significant negative impacts, because: unbalance the ecosystem, being direct competitors for food and habitat of endemic ou naturals; atack rural plantations, mainly, causing significant economic losses; can also, on the cross pigs (Sus scrofa domesticus) amu range can transmit diseases and interfere negatively trade not pork catarinense meat, mainly or external. work was to evaluate this target different types of bait - mineral salt, corn, naturals and fuel diesel - not monitoring populations wild of boar was accomplished in native forest area company pertaining to agricultural research and extension of Santa Catarina - EPAGRI, experimental station Caçador, to Propose to prove on two especims effectiveness in attracting. To find out you economie impacts caused by populations of boar, corn planting 60 acres, that belongs to the farm Rio dos Patos, located between the municipalities of Caçador and Lebon Régis, evaluated for the presence of species of boar and the damage number of plants for pigs, during the month of February 2012. Photographic records were made as well as getting testimonials from farmers in the region to support the facts reported. It can be concluded from the work bait with higher activity of the animal was attack corn. Well as the area where the animal attacked some crops in the region, preying almost $70 \%$ of the area planted.

Keywords: Sus scrofa, javali, ceva, wild boar.

\section{INTRODUÇÃO}

Espécies exóticas invasoras são organismos provenientes de outras regiões que conseguiram se estabelecer no novo ambiente e são reconhecidas como uma das principais ameaças à biodiversidade local, ocasionando grandes impactos negativos às atividades agropastoris e à saúde humana (WITTENBERG; COCK, 2001). O javali (Sus scrofa), originário da Eurásia (WILSON; REEDER, 2005), é uma espécie exótica no território brasileiro e, nos últimos anos, tem apresentado aumento populacional descontrolado.

Por não possuir predador natural nos novos ambientes em que se adaptaram, espécimes de javali vêm ocasionando impactos negativos tanto aos ecossistemas, interferindo nos nichos de espécies naturais, quanto à economia, degradando extensas áreas de plantações rurais, notavelmente 
as de milho (SALVADOR et al. 2012).

O porco doméstico (Sus scrofa domesticus) é resultado de cerca de nove mil anos de domesticação e melhoramento genético de uma espécie selvagem que, no Brasil, é conhecida como javali (LARSON et al., 2005). Aqui, entretanto, a denominação javali também é atribuída a porcos domésticos que escaparam do cativeiro e tiveram vida livre na natureza, conhecidos como porcos ferais. E, para fins de manejo, esses espécimes também serão tratados como javali.

Segundo o levantamento agropecuário realizado pela Secretaria Estadual da Agricultura e Desenvolvimento Rural (SAR, 2003), Santa Catarina contava com mais de 500 produtores ilegais de javali, que juntos apresentavam cerca de cinco mil cabeças. O aumento populacional descontrolado de javalis também pode se tornar uma grande ameaça a um dos principais fatores da economia catarinense, o comércio externo de carne suína, devido ao risco de contaminação de doenças aos porcos das granjas produtoras.

De acordo com diversos autores (LOWE et al.2000), o javali pode afetar negativamente muitos outros processos, pois: apresentam 0 comportamento de revirar o solo, afetando a dinâmica deste; alimentam-se de aves e de ovos de espécies que nidificam no solo; depredam bancos de sementes e alteram a capacidade regenerativa da floresta; competem com espécies de porcos-do-mato nativos e ameaçados de extinção, como o cateto, Pecari tajacu e o queixada, Tayassu pecari, entre outros.

Devido ao fato das regiões pertencentes à Floresta de Araucária ter um histórico recente de uso intenso, com criação tradicional de suínos e exploração da erva mate (llex paraguariensis) e madeireira, os suínos eram criados soltos para engorda, utilizando-se o mínimo de insumos, especialmente na época da frutificação da araucária. Além disso, relatos 
históricos comprovam que porcos asselvajados eram comuns na região $(B A C H, 2009)$. A criação de suínos foi tão intensa nessa região que chegou a ser uma das principais atividades econômicas do Brasil nos anos 1930-50 (BACH, 2009) e se desenvolveu para uma das maiores produtoras atuais de suínos do mundo (FAO 2007; SALVADOR, et al. 2012). Dentro desse contexto, o javali é uma das cem espécies invasoras que mais causa transtornos de ordem financeira, pois ataca lavouras e altera todo o ecossistema devido ao consumo de sementes e competição de nichos com espécies nativas (SALVADOR et al. 2012). Relatos informam que grupos de javalis são capazes de comer um hectare de lavoura em poucos dias (WITTENBERG; COCK, 2001).

O Comitê de Espécies Exóticas de Santa Catarina e gestores de áreas protegidas têm apontado a falta de informações básicas sobre a biologia do javali e sobre métodos de controle como as principais dificuldades no manejo dessa espécie (FATMA, 2009; APREMAVI, 2009). Devido a isso, este trabalho tem como objetivo principal avaliar diferentes tipos de ceva - sal mineral, milho e combustível diesel - no monitoramento de populações selvagens de javali, realizada em área de mata nativa pertencente à Empresa Agropecuária de Pesquisa e Extensão Rural de Santa Catarina - EPAGRI, Estação Experimental de Caçador, com a finalidade de verificar a efetividade na atração dos espécimes. Para averiguar os impactos econômicos ocasionados por populações de javali, uma plantação de milho com sessenta (60) hectares, pertencente à fazenda Rio dos Patos, localizada na divisa entre os municípios de Caçador e Lebon Régis, foi avaliada quanto à presença de espécimes de javali e ao número de plantas danificadas por eles durante o mês fevereiro do ano de 2012. Registros fotográficos foram feitos bem como a obtenção de depoimentos de agricultores da região para corroborar os fatos relatados. 


\section{PROCEDIMENTOS METODOLÓGICOS}

O presente estudo foi desenvolvido no município de Caçador, região centro-oeste do Estado de Santa Catarina, situando-se entre as coordenadas geográficas $50^{\circ} 59^{\prime}$ e $50^{\circ} 53^{\prime}$ de longitude Oeste de Greenwich e de $26^{\circ} 49^{\prime}$ e $26^{\circ} 53^{\prime}$ de latitude Sul, com altitude que varia de 900 a 1.104 metros, (EMBRAPA, 2005). O bioma predominante é a Mata Atlântica, ecossistema Floresta de Araucária, sendo o clima subtropical úmido.

A área para a introdução de cevas pertence à Reserva Florestal da EMBRAPA/EPAGRI e foi declarada área de utilização pública há aproximadamente 56 anos, através do Decreto $n^{\circ} 25.407$, de 30 de agosto de 1948. Essa área é um dos maiores remanescentes contínuos (1.157,5 ha) de vegetação característica do bioma Floresta Ombrófila Mista. A análise de diferentes tipos de cevas para o monitoramento de populações selvagens de javali (Sus scrofa) realizou-se nessa região florestal por abrigar significativos remanescentes de árvores de araucária, cuja semente é muito atrativa para o javali, principalmente nos meses mais frios do ano.

Para a determinação dos locais de ceva, realizou-se uma trilha em transecto contínuo na Reserva Florestal da EMBRAPA/EPAGRI, totalizando $22 \mathrm{~km}$ de caminhada e dez horas diárias, nos períodos de 06/06/2011 a 22/10/2011. Verificaram-se as áreas que apresentavam maior densidade de vestígios de javali a fim de se estabelecer pontos para o desenvolvimento de cevas. Os locais designados foram os que apresentaram pegadas, vestígios de fuçado e restos orgânicos do animal. Foram estabelecidos 18 pontos de ceva, divididos de acordo com a isca utilizada: milho, sal mineral, combustível diesel e natural (locais onde nitidamente houve a presença de javali para a alimentação com sementes de araucária, raízes de plantas ou espécies vegetais). Desse total, foram 
estabelecidas sete (7) cevas de milho, seis (6) cevas contendo sal mineral e cinco (5) cevas com óleo diesel. As cevas naturais foram utilizadas apenas para a verificação da interferência dos javalis nos sistemas naturais, depredando espécies nativas de plantas. Além disso, as cevas foram divididas de acordo com a localização e aspectos do local em: próximas a locais úmidos, como banhados, rios e córregos e rica em vegetação nativa (cevas: 03, 05, 13, 10 e 12) e áreas com a presença de vegetação rasteira, campestre e com menor diversidade arbórea (cevas: $01,02,04,06,07,08,09,11,13,14,15,16,17$ e 18)

Depois de estabelecidas as cevas, monitoramentos semanais foram realizados por um período de seis (6) meses para verificar quais eram as áreas mais visitadas pelos espécimes de javali, buscando alterações diretas nas devidas cevas e vestígios no local. Consideraram-se cevas diretamente alteradas aquelas em que os vestígios de javali se encontraram sobre o alimento colocado na ceva, ou ainda quando houve nítida alimentação do material. Para averiguar a efetividade na atração de animais pelas cevas foram analisadas as seguintes variáveis, descritas nos impactos econômicos ocasionados por populações de javali foram avaliados em uma plantação de milho com sessenta (60) hectares, pertencente à fazenda Rio dos Patos, localizada na divisa entre os municípios de Caçador e Lebon Régis, durante o mês fevereiro do ano de 2012. Para tal, realizaram-se registros fotográficos e obtidos depoimentos de agricultores. As visitas à propriedade ocorreram nos dia 15, 22 e 29/02/2012, com duração de sete (7) horas cada uma, sendo percorridas diversas áreas da propriedade e cuja caminhada excedeu os dez (10) km diários.

As plantações da propriedade obedecem ao plantio direto, sendo o espaçamento entre plantas de $0,40 \mathrm{~m}$ e entre carreiras de 0,30 m. 
Escolheram-se amostras completamente ao acaso, sendo compostas por dez parcelas, cada parcela composto por duas carreiras, tendo dez metros de comprimento. Para a verificação do dano econômico ocasionado à plantação, a porcentagem verificada nessas parcelas foi estimada para a plantação total, utilizando teste de variância.

\section{RESULTADOS E DISCUSSÕES}

Dos 109,10 há, 60 ha é lavoura de milho, localizando-se em uma ampla faixa de vegetação ombrófila e, devido a esse fato, local de extrema predominância do javali, que vinha frequentemente devorando e ocasionando vários estragos na lavoura de milho. (CASTILHO, José Antônio, informação sobre registro de ataque de javali, 13/02/2012). Avistaram-se diversos vestígios, dentre eles um crânio de um javali (aparentemente 2 anos de idade pelo tamanho), comprovando o fato. Após mais duas visitas à propriedade, uma no dia 22/02 e outra 29/02, foi possível calcular uma estimativa do prejuízo causado pelo animal.

O proprietário, que forneceu informações referente ao tipo de plantio utilizado, ajudando nos cálculos estatísticos, utilizou-se do plantio direto, ou seja, o espaçamento entre as plantas é de 0,40 $\mathrm{m} \times 0,30 \mathrm{~m}$. Isso facilitou na coleta de dados. Com o levantamento de informações, foi possível colher amostras nas clareiras feitas pelo animal na roça de milho, procedendo-se da seguinte maneira: escolha de duas carreiras de milho das mais prejudicadas pelo ataque, dessas carreiras demarcaram-se 10 (dez) metros de comprimento e contabilizou-se o número de plantas atacadas e plantas intactas. Com isso, foi possível descrever quantas plantas a cada dez metros de amostras foram totalmente destruídas pela espécie exótica. Os resultados obtidos através do estudo de diferentes 
tipos de cevas possibilitou o entendimento da mais procurada pela espécie, sendo alterada com frequência e passando a utilizar o local como fonte de alimento e sobrevivência. Baseado nas evidências, pode-se verificar que nem todas as cevas foram frequentadas periodicamente, sendo que em alguns períodos, certas cevas foram totalmente intocadas pelo javali (Sus scrofa). Isso pode estar relacionado ao fato de ter sido comprovada a presença de caçadores na região. Fato que poderia ter assustado as populações de javali ou mesmo as matado. De acordo com a Tabela 01 a seguir, podem-se notar as frequências de visitas de javali em determinadas cevas e discriminadas pelos dias visitados. Para realizar essa tabela, utilizaram-se amostragens de monitoramentos realizados apenas no mês de outubro de 2011, devido ao fato de o animal estar em uma alta procura por alimento nessa época.

Tabela 1: Quantidade de vestígios e alterações em cevas de milho, sal e diesel durante o mês de outubro, no interior do município de Caçador, no ano de 2011 


\begin{tabular}{|c|c|c|c|c|c|c|c|c|c|c|}
\hline \multicolumn{2}{|c|}{ DATAS } & \multicolumn{3}{|c|}{$08 / 10 / 2011$} & \multicolumn{3}{|c|}{$15 / 10 / 2011$} & \multicolumn{3}{|c|}{$22 / 10 / 2011$} \\
\hline \multicolumn{2}{|c|}{$\begin{array}{c}\text { TIPO E } \\
\text { NÚMERO } \\
\text { DA CEVA }\end{array}$} & $\begin{array}{c}\text { ALTERA } \\
\text { DA }\end{array}$ & $\begin{array}{c}\text { VESTÍGI } \\
0\end{array}$ & $\begin{array}{c}\text { SEM } \\
\text { ALTERAÇ } \\
\text { Ão }\end{array}$ & $\begin{array}{c}\text { ALTERA } \\
\text { DA }\end{array}$ & $\begin{array}{c}\text { VESTÍGI } \\
0\end{array}$ & $\begin{array}{c}\text { SEM } \\
\text { ALTERAÇ } \\
\text { Ão }\end{array}$ & $\begin{array}{c}\text { ALTERA } \\
\text { DA }\end{array}$ & $\begin{array}{c}\text { VESTÍGI } \\
0\end{array}$ & $\begin{array}{c}\text { SEM } \\
\text { ALTERAÇ } \\
\text { Ão }\end{array}$ \\
\hline \multirow{7}{*}{$\begin{array}{c}\text { MILH } \\
0\end{array}$} & 1 & 0 & 1 & 0 & 0 & 0 & 1 & 0 & 0 & 1 \\
\hline & 2 & 1 & 1 & 0 & 0 & 0 & 0 & 0 & 0 & 1 \\
\hline & 3 & 1 & 1 & 0 & 1 & 1 & 0 & 1 & 1 & 0 \\
\hline & 4 & 1 & 1 & 0 & 1 & 1 & 0 & 1 & 1 & 0 \\
\hline & 5 & 1 & 1 & 0 & 1 & 1 & 0 & 1 & 1 & 0 \\
\hline & 6 & 0 & 1 & 0 & 0 & 1 & 0 & 0 & 0 & 1 \\
\hline & 7 & 1 & 1 & 0 & 1 & 1 & 0 & 0 & 1 & 0 \\
\hline \multirow{6}{*}{ SAL } & 8 & 0 & 1 & 0 & 1 & 1 & 0 & 1 & 1 & 0 \\
\hline & 9 & 0 & 1 & 0 & 1 & 1 & 0 & 0 & 1 & 0 \\
\hline & $\begin{array}{l}1 \\
0\end{array}$ & 0 & 0 & 1 & 0 & 1 & 0 & 0 & 0 & 1 \\
\hline & $\begin{array}{l}1 \\
1 \\
\end{array}$ & 0 & 1 & 0 & 0 & 1 & 0 & 0 & 0 & 1 \\
\hline & $\begin{array}{l}1 \\
2\end{array}$ & 0 & 1 & 0 & 1 & 1 & 0 & 1 & 1 & 0 \\
\hline & $\begin{array}{l}1 \\
3\end{array}$ & 0 & 1 & 0 & 1 & 1 & 0 & 0 & 1 & 0 \\
\hline \multirow{5}{*}{$\begin{array}{c}\text { DIESE } \\
\mathbf{L}\end{array}$} & $\begin{array}{l}1 \\
4\end{array}$ & 1 & 1 & 0 & 0 & 1 & 0 & 1 & 1 & 0 \\
\hline & $\begin{array}{l}1 \\
5\end{array}$ & 1 & 1 & 0 & 1 & 1 & 0 & 1 & 1 & 0 \\
\hline & $\begin{array}{l}1 \\
6\end{array}$ & 0 & 1 & 0 & 1 & 1 & 0 & 0 & 1 & 0 \\
\hline & $\begin{array}{l}1 \\
7\end{array}$ & 1 & 1 & 0 & 0 & 1 & 0 & 1 & 1 & 0 \\
\hline & $\begin{array}{l}1 \\
8\end{array}$ & 1 & 1 & 0 & 1 & 1 & 0 & 1 & 1 & 0 \\
\hline \multicolumn{2}{|c|}{$\begin{array}{c}\text { TOTAL/DA } \\
\text { TA } \\
\end{array}$} & 9 & 17 & 1 & 11 & 16 & 1 & 9 & 13 & 5 \\
\hline
\end{tabular}

A numeração 1 indica "sim" e 0 indica "não". Os vestígios ocorreram de forma independente ou associadas às alterações das cevas. Para essa última situação, as duas primeiras colunas de cada data apresentam numeração 1, demonstrando que ocorreram simultaneamente.

Baseando-se na tabela, as cevas alteradas e com vestígios do animal recebem o número 1 que indica presença (o animal passou a utilizar); as que não receberam visitas do animal ou não possuem vestígios recebem o número 0 , resultando 12 visitas às cevas de milho, sendo essa a principal isca, a mais atrativa ao animal. Nos monitoramentos realizados, pode-se afirmar que a isca feita com milho foi aceita como maior índice de aproveitamento, constatando-se que é viável a preparação de cevas utilizando milho em casos de controle de populações baseadas na 
confecção de iscas devido ao fato de o animal estar ocasionando grandes perdas na produção agrícola em geral, afetando indiretamente a parte financeira do estado. Com uma prova em mãos e sabendo que o animal pode ocasionar grandes perdas no meio agrícola, surgiu um caso real de ataque à lavoura de milho, na fazenda Rio dos Patos interior do município de Caçador divisa com município de Lebon Régis.

No dia 15/02/2012, a visita realizou-se, percorreram-se diversas áreas da propriedade e avistaram-se diversos vestígios, entre eles um crânio de javali aparentemente 2 anos de idade pelo tamanho, comprovando que era realmente o javali (Sus scrofa). Após mais duas visitas à propriedade com diferença de 10 dias entre uma e outra, foi possível calcular uma estimativa do prejuízo causado pelo animal. De acordo com o proprietário, que passou informações referente ao método utilizado no plantio ajudou a calcular os prejuízos. Utilizou-se um método conhecido como plantio direto sendo o espaçamento entre as plantas de $0,40 \mathrm{~m} \times 0,30 \mathrm{~m}$. Isso facilitou na coleta de dados.

O gráfico abaixo demonstra a quantidade de plantas abatidas pelo animal dentre as amostras escolhidas. 


\section{Quantidade de plantas atacadas em 10 amostras coletadas dadas em \%}

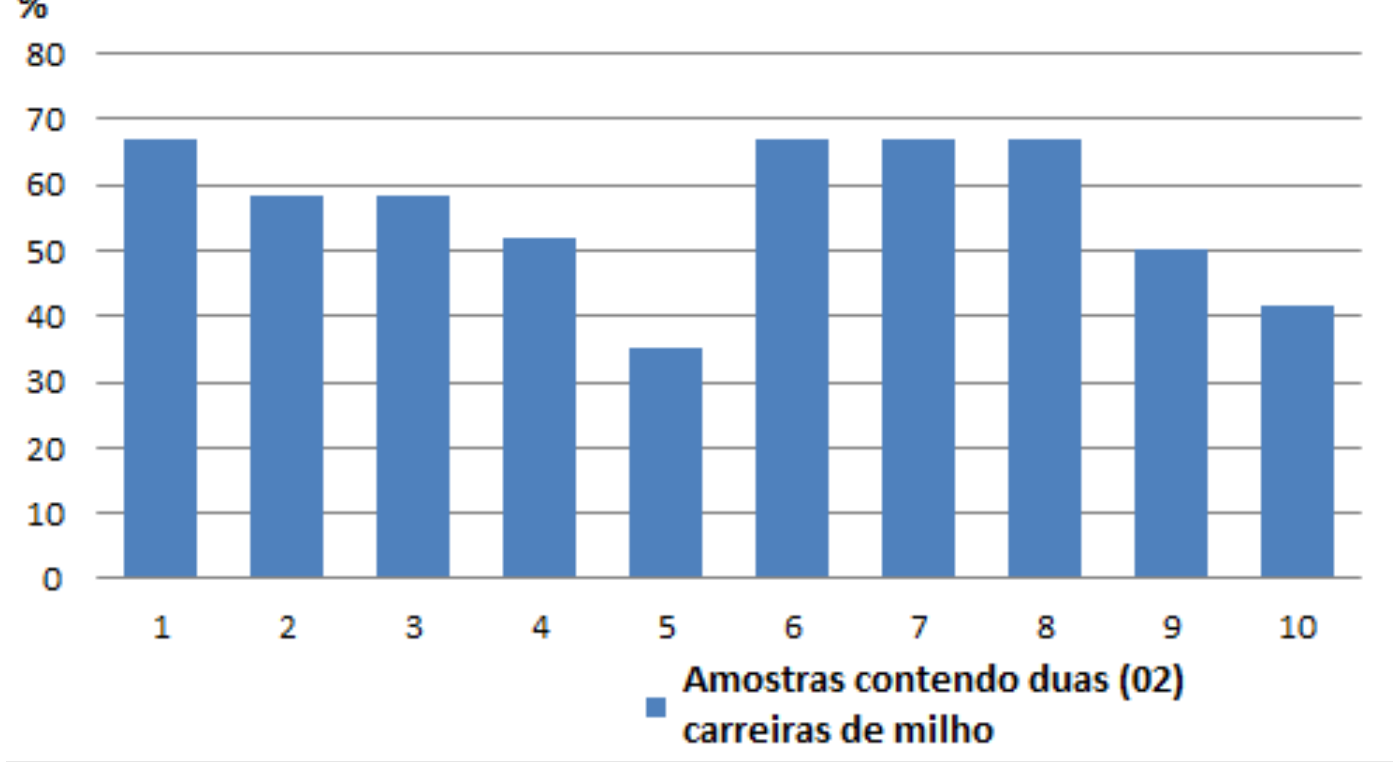

Baseando-se nos cálculos das amostragens acima mencionadas, as quais resultaram em: no gráfico, as barras de cor azul demonstram as amostragens constituídas de duas carreiras de milho, sendo que cada carreira possuía 30 pés de milho plantado. Os valores no eixo vertical estão em porcentagem, significa o total de pés de milho que 0 animal atacou.

\section{REFERÊNCIAS}

ALHO, C.J.R.; LACHER Jr., T.E.; CAMPOS, Z.M.; GONÇALVES, H.C. Mamíferos da fazenda Nhumirim, sub-região da Nhecolândia, Pantanal do Mato Grosso do Sul: levantamento preliminar de espécies. Revista Brasileira de Zoologia, v.2, p. 151-164, 1987.

CAIPORA. Projeto Javali. Programa de Manejo de Vida Silvestre. Caipora Cooperativa para Conservação da Natureza, 2009. Disponível em: <www.caipora.org.br>. Acesso em: 10 nov. 2009. 
CHOQUENOT, D.; SAUNDERS, G.. A comparison of three ageing techniques for feral pigs from subalpine and semi-arid habitats. [s.l.:s.n.], 1993.

MCILROY, J. C.; BRAYSHER, M.; SAUNDERS, G. R. Effectiveness of a warfarin-poisoning campaign against feral pigs, Sus scrofa, in Namadgi National park, Australian Capital Territory. Australian Wildlife Research, v. 16, p. 195-202, 1989. Doi:10.1071/WR9890195.

MCILROY, J. C.; GIFFORD, E. J.; FORRESTER, R. I. Seasonal atterns in bait consumption by feral pigs (Sus scrofa) in the hill country of southeastern Australia. Wildlife Research, v. 20, p. 637-651.

OLIVEIRA, Y. M. M. de. Investigation of remote sensing for assessing and monitoring the araucaria forest of Brazil. Oxford, UK, 2000. 247p. Tese. (Doutorado em Ciências Florestais) University of Oxford. Disponível em: <http://www.appio.com.br/arquivos/v160a.pdf>. 